\title{
A LEGISLAÇÃO EDUCACIONAL BRASILEIRA DE 1930 A 1961 COM RELAÇÃO À PESSOA COM DEFICIÊNCIA
}

\author{
Elaine Maria Bessa Rebello Guerreiro ${ }^{1}$ \\ Tereza Cristina Rodrigues Villela ${ }^{2}$
}

\section{RESUMO}

Vivemos outro modelo de concepção da deficiência e da pessoa com deficiência, sobretudo, sobre suas potencialidades e possibilidades educacionais. No entanto, em um passado não tão distante, a educação da pessoa com deficiência era vista de uma forma diferente da educação em geral. Esse modo de educação era característico do que se pensava, à época, sobre a pessoa com deficiência. Desta forma, o objetivo deste artigo foi refletir sobre a condição da pessoa com deficiência nas legislações educacionais nas décadas de 1930, 1940 e 1950, até a promulgação da primeira Lei de Diretrizes e Bases da Educação Nacional em 1961. Para tanto, buscou-se estudar artigos, textos e leis que tratam da questão. Apesar dos avanços nos dias atuais, nota-se uma dicotomia entre os direitos presentes na legislação existente em âmbito nacional, e nos tratados internacionais, e a efetivação dos mesmos.

Palavras-chave: Educação Especial; Inclusão escolar; Pessoa com deficiência; Política educacional.

\section{BRAZILIAN EDUCATIONAL LEGISLATION FROM 1930 TO 1961, AS TO THE PERSON WITH DISABILITIES}

\begin{abstract}
We experience another conception model of disability and of the disabled person, mainly when regarding their educational potentialities and possibilities. However, in a past not so far, education of the disabled person was perceived as different from general education. This education mode was typical to its period. This way, the aim of this article was to reflect about the disabled person's condition in the educational legislation in the decades of 1930, 1940 and 1950, until the enactment of the first Law of Directives and Bases of National Education in 1961. For that, we sought to study articles, texts and laws which address the issue. In spite of the actual advancements, it is easy to notice a dichotomy between the rights present in the national legislation (and in international treaties) and their effectiveness.
\end{abstract}

Keywords: Special Education. School inclusion. Disabled Person. Educational Policy.

\section{Introdução}

Segundo Ferreira (1994), a educação da pessoa com deficiência teve uma trajetória diferente da educação em geral. No período de 1876 a 1935 prevaleceu o modelo médicopedagógico e psicopedagógico na forma de ver a pessoa com deficiência. Esse olhar direcionou os esforços para a cura, o tratamento e a dependência da pessoa com deficiência em relação às outras pessoas. Via-se o deficiente e não a deficiência, suas limitações, não suas possibilidades, confinando-o em ambientes restritivos ou isolados. Este modelo prevaleceu hegemônico por muito tempo e foi mudando conforme novos rumos e formas de tratar a questão foram surgindo. 
Embora as legislações educacionais das décadas de 1930 e 1940 destaquem a exclusão da pessoa com deficiência enquanto aluno da escola regular, as Constituições, desde a de 1824, mencionam que a educação é direito de todos, supondo-se, portanto, que a pessoa com deficiência estivesse inserida. Nos casos das legislações educacionais, quando tratavam da matrícula do aluno, traziam condições impeditivas da inserção do aluno com deficiência ou, pelo menos, geravam dúvidas quanto a sua matrícula na escola. Somente a partir da promulgação da Lei no 4.024/61 (BRASIL, 1961), que regulamenta as Diretrizes e Bases da Educação Nacional (LDB), é que aparece o termo educação de excepcionais (Art. 88). Nas décadas seguintes, a educação da pessoa com deficiência vai ocupando cada vez mais o seu espaço através do empenho de educadores, organizações civis e associações das pessoas com deficiências (JANNUZZI, 2006).

Desta forma, o objetivo deste artigo foi refletir sobre a condição da pessoa com deficiência nas legislações educacionais das décadas de 1930 e 1940, até a promulgação da primeira Lei de Diretrizes e Bases da Educação Nacional (LDB), em 1961. O recorte da época se deu por dois motivos: o primeiro por causa da criação do Ministério dos Negócios da Educação e Saúde, em 1930, até a promulgação da nossa primeira LDB; o segundo foi originado pelas condições de matrícula do aluno enquanto constituição de barreira para o acesso da pessoa com deficiência no sistema educacional. Buscou-se estudar artigos, textos e leis que tratam da questão educacional, no sentido de observar como se percebia a pessoa com algum tipo de deficiência, no período citado. Após essa exposição, far-se-á uma breve comparação com o atual panorama sobre as os direitos da pessoa com deficiência, seus avanços na legislação e questões ainda pendentes.

Neste estudo é adotada a terminologia "pessoa com deficiência" ao se referir à população de pessoas com deficiência física, sensorial ou intelectual. Essa mesma terminologia recebeu, no entanto, variadas denominações, ao longo do tempo, nos documentos e legislações investigados. Ao se reportarem à pessoa com algum tipo de deficiência ou necessidade especial, os materiais aqui analisados empregam, entre outros, as nomenclaturas "deficientes", "anormais", "cegos", "surdo-mudo", "retardados da inteligência", "excepcional". E para alguns estudiosos, como Sigolo, Guerreiro e Cruz (2010), os termos tais como "idiotas, retardados, ineducáveis", mais prejudicaram do que ajudaram.

\section{Panorama educacional de 1930 a 1961}

Segundo Jannuzzi (2006), a partir de 1930, a sociedade civil começou a organizar-se em associações preocupadas com os problemas da deficiência. Na esfera governamental, foram desencadeadas ações que atendessem às particularidades educacionais e de saúde da pessoa com deficiência. Nesse último sentido, a criação do Ministério dos Negócios da Educação e Saúde Pública, no governo provisório de Getúlio Vargas, em 1930, através do Decreto $\mathrm{n}^{\circ}$ 19.402, de 14 de fevereiro de 1930 (BRASIL, 1930b) foi um marco.

E, de acordo com Shirona, Moraes e Evangelista (2007), essa era uma antiga reinvindicação de educadores e intelectuais brasileiros. Essas autoras destacam que a estrutura de ensino no Brasil, até 1930, não contava com uma política nacional de educação que prescrevesse diretrizes gerais e nem indicavam a que ou a quem os sistemas estaduais deveriam estar subordinados. Nesse ministério, portanto, inaugurou-se uma fase de mudanças em todo o território nacional com uma série de decretos conhecidos como Reformas Francisco Campos.

Destaca-se que a Constituição vigente, à época, era a de 1891 (BRASIL, 1891) e, nesta, a educação era tratada no item $30^{\circ}$ do Art. 34 , nos itens $2^{\circ}, 3^{\circ}$ e $4^{\circ}$ do Art.35, e no 
inciso $6^{\circ}$ do Art. 72, de uma forma esparsa e não muito clara. Até este período, para que tenhamos um exemplo contundente do que até agora se expôs, os analfabetos não podiam votar. Faria e Faria (2005) afirmam que o índice de analfabetismo no Brasil, em 1920, era de $64,90 \%$ e, em 1930 , era de $56 \%$. A falta de uma política nacional de educação, desta feita, refletia diretamente no campo sócio-político.

Com a criação desse ministério, o governo provisório sancionou decretos, organizando o ensino secundário e as universidades, até então inexistentes no país. Bello (2001) diz que a entrada do Brasil no mundo capitalista de produção exigiu uma mão de obra especializada, sendo, portanto, necessário o investimento na educação. Com esse modelo urbano-industrial passou-se a fazer solicitações à escola, pois o equilíbrio estrutural do sistema educacional foi afetado pela inclusão de novas e crescentes necessidades de recursos humanos para ocupar funções nos setores secundários e terciários da economia (SANTOS, 2007b).

A questão educacional brasileira, por outro lado, já vinha sendo debatida desde o início da República, por que já se compreendia todo o processo que ali começava a se avistar. E para essa discussão sobre seus novos rumos foi imprescindível que buscasse o envolvimento de vários setores organizados da sociedade, os quais discutiam, sobretudo, a necessidade de uma reforma educacional que atendesse ao processo de modernização da na época (ANDREOTTI, 2004). Foi esse contexto, que surgiram movimentos educacionais importantes, como a escola nova.

O movimento escolanovista, outra denominação da escola nova, desde a década de 1920, vinha influenciando os educadores e intelectuais da época e, em 1932, o "Manifesto dos Pioneiros da Educação Nova" é lançado, definindo os pontos principais que deveriam ser discutidos no âmbito educacional. Os responsáveis pelo movimento buscavam uma identidade brasileira e acreditavam que a educação era fundamental para a reconstrução nacional e necessária para o estabelecimento de leis que regessem o sistema educacional brasileiro, já pensando na lei de diretrizes da educação (SANTOS, 2006). Esse manifesto visava à concretização de um dos princípios máximos que era o direito de todos à educação.

Porém a escola pública e gratuita consistia em um risco para as escolas privadas e a extensão da escolarização a todas as camadas se constituía em uma evidente ameaça para os privilégios já assegurados às elites (SANTOS 2007b). Nesse embate de forças que compreende os períodos de 1948 a 1961 foi que ocorreu a tramitação do projeto da primeira LDB. De acordo com Davies (2009), esse embate foi caracterizado como uma luta entre os interesses privatistas e os defensores da manutenção e difusão da escola pública, gratuita e laica.

No governo provisório da Revolução de 1930, elaborou-se a Constituição da República dos Estados Unidos do Brasil, datada em 16 de julho de 1934 (BRASIL, 1934a). O Capítulo que trata da educação e cultura menciona que a educação é direito de todos (Art. 149) e, na letra "a" do parágrafo único do Art. 150, diz-se que o ensino primário é integral e gratuito.

No Estado Novo, com a Constituição dos Estados Unidos do Brasil, em 10 de novembro de 1937 (BRASIL, 1937), permaneceu a menção do ensino primário obrigatório e gratuito, porém a frase a educação é direito de todos foi retirada, voltando a aparecer na Constituição de 1946. Através da Lei no 378/37, o Ministério dos Negócios da Educação e Saúde Pública passou a ser chamar Ministério da Educação e Saúde (JANNUZZI, 2006).

Em 18 de setembro de 1946 (BRASIL, 1946a) foi promulgada a nova Constituição brasileira que seguia as mesmas orientações das anteriores, tais como, a educação é gratuita e obrigatória no ensino primário, e é um direito de todos. De acordo com Cury (2008), a 
Constituição de 1946 retomou os princípios da Constituição de 1934, tais como o da vinculação de impostos para o financiamento, a educação como direito, a gratuidade e obrigatoriedade do ensino primário.

Sob essa Constituição, após debates entre publicistas e privatistas, foi sendo construída a nossa primeira LDB, promulgada em 1961 (CURY, 2008). Com a criação do Ministério da Saúde, através da Lei 1.920/53 (BRASIL, 1953), o Ministério da Educação e Saúde Pública passou a ser chamado de Ministério da Educação e Cultura.

$\mathrm{Na}$ Lei $\mathrm{n}^{\circ}$ 4.024/61 (BRASIL, 1961) aparece, pela primeira vez, a educação da pessoa com deficiência (educação de excepcionais). Apesar de mencionar que a educação é direito de todos, deixa brechas para que o ensino primário obrigatório não fosse integralmente cumprido, ao mencionar, no Art. 30, as isenções da obrigatoriedade. Deixa explícito quem não precisa ser destinatário da educação escolar: os que comprovarem estado de pobreza, os que não puderem ir à escola por haver insuficiência de escolas ou por estas já terem suas matrículas encerradas, ou que estejam com alguma doença ou anomalia grave.

\section{A educação da pessoa com deficiência}

O Decreto $n^{\circ}$ 19.850/31 (BRASIL, 1931a) criou o Conselho Nacional de Educação, que tinha entre suas atribuições firmar as diretrizes do ensino primário, secundário, técnico e superior, atendendo, acima de tudo, os interesses da civilização e da cultura do país. Porém para as pessoas com deficiências era reservado outro modelo educacional. De acordo com Jannuzzi (2006), a partir de 1930 foi utilizado o termo "ensino emendativo", expressão empregada por muitos educadores ao se referirem à educação dos deficientes.

Para Jannuzzi (2006), a expressão ensino emendativo representa o pensamento à época sobre a educação da pessoa com deficiência, que na fala de Armando Lacerda (1934, apud Jannuzzi, 2006), tem a finalidade de suprir as falhas decorrentes da anormalidade, visando adaptar o educando ao nível social dos ditos normais. Para isso foi criado, através do Decreto $\mathrm{n}^{\circ}$ 24.794/34 (BRASIL, 1934b), dentro do Ministério da Educação e Saúde Pública, a Inspetoria Geral do Ensino Emendativo. No preâmbulo desse Decreto se encontram várias considerações para a sua promulgação, dentre elas, esta a seguir, na qual se afirma que

Considerando que os anormais, nas suas diferentes categorias ou tipos, podem se adaptar, na sua maioria, ao meio social, desde que sejam submetidos a processos de educação adequados à sua deficiência física, sensorial ou psíquica, e atendendo a que a Constituição da República, a ser promulgada, torna obrigatório o ensino e assistência geral aos desvalidos e que esta será muito menos onerosa uma vez que se promova a conversão, pelo ensino, dos anormais em cidadãos úteis e capazes.

Observa-se que há uma preocupação com o ônus para a sociedade da pessoa sem uma atividade laboral que pode ser proporcionada pelo ensino e pela ordem. A concepção na época sobre a pessoa com deficiência abrangia desde as deficiências físicas e sensoriais até problemas de comportamento, como pode ser observado no Art. $3^{\circ}$ desse Decreto.

Art. $3^{\circ}$ Atendendo à destinação específica dos estabelecimentos de que trata o artigo anterior e em face da finalidade do seu conjunto, que é o aproveitamento e o corretivo possível dos anormais do físico, dos sentidos, da moral e da mente, com o objetivo utilitário social ao lado da proteção caritativa, o Ensino Emendativo inicialmente será ministrado nos seguintes estabelecimentos: 

a) institutos para cegos;
b) institutos para surdos-mudos;
c) escolas de prevenção;
d) escolas de correção;
e) escolas reformatórias;
f) patronatos agrícolas.

No parágrafo primeiro desse artigo, diz-se que as Escolas 15 de Novembro, 7 de setembro e João Luiz Alves, instituições oficiais de atendimento infanto-juvenil, as quais estavam subordinadas ao Ministério da Justiça e Negócios Interiores, passariam para o Ministério da Educação e Saúde Pública. De acordo com Bazílio e Müller (2006), em 1937, Gustavo Capanema, ministro da Educação e Saúde Pública, propõe o cumprimento desse parágrafo, o que não foi acatado, tendo sido mantido no âmbito apenas da Justiça.

Ainda com relação ao Ensino Emendativo, no livro "A educação nas mensagens presidenciais", vol. 1 e 2 (INEP, 1987a; INEP, 1987b), pode-se observar sua abrangência e aplicação. Em 1936, o presidente Getúlio Vargas se referiu ao Instituto Benjamin Constant ${ }^{3}$ e ao Instituto Nacional de Surdos-Mudos ${ }^{4}$, como responsáveis pelo ensino emendativo. Já em 1937, referiu-se a esse ensino como sendo de "aplicação difícil e restrita" (INEP, 1987a), indicando o alunado e lócus de trabalho (Quadro 1). Em 1957, o presidente Juscelino Kubitschek de Oliveira, na abertura da sessão legislativa, falou do ensino emendativo e supletivo somente com relação aos cegos e surdos-mudos (INEP, 1987b).

QUADRO 1 - Ensino emendativo, alunado e lócus preferencial

\begin{tabular}{|l|l|}
\hline \multicolumn{1}{|c|}{ ALUNADO } & \multicolumn{1}{c|}{ LÓCUS } \\
\hline Fisicamente anormais & Instituto Benjamin Constant e o Instituto Nacional de Surdos e Mudos \\
\hline Retardados de inteligência & $\begin{array}{l}\text { A ação do poder público se exercerá de acordo com as normas fixadas pelo Instituto } \\
\text { Nacional de Pedagogia, em conexão com o Serviço de Assistência a Psicopatas }\end{array}$ \\
\hline Inadaptados morais & A cargo do Ministério da Justiça \\
\hline
\end{tabular}

Fonte: As autoras, adaptado de INES (1987a) e INES (1987b).

De acordo com o Instituto Brasileiro de Geografia e Estatística (IBGE, 1941), as matrícula, entre 1932 e 1938, no Ensino Emendativo foram estáveis, porém, com um maior aumento na conclusão de curso (Tabela 1). Esses dados são contestados por Jannuzzi (2006, p. 77-78), que relata as dificuldades de generalização decorrentes das informações não coincidentes de matrículas entre o IBGE de 1937 e a estatística do CENESP $^{5}$ de 1975.

Tabela 1 - Ensino Emendativo de 1932 a 1938

\begin{tabular}{c|c|c|c|c|c|c|c}
\hline Ano & \multirow{2}{*}{ Unidade } & Docente & \multicolumn{2}{|c|}{ Matrícula } & Frequência & Aprovação & $\begin{array}{c}\text { Conclusão } \\
\text { de curso }\end{array}$ \\
\cline { 4 - 5 } & & & Geral & Efetiva & & & 72 \\
\hline 1932 & 31 & 132 & 2.242 & - & 2.102 & - & 97 \\
\hline 1933 & 38 & 176 & 2.842 & - & 2.561 & - & 361 \\
\hline 1934 & 53 & 200 & 3.321 & 3.119 & 2.760 & 1.108 & 536 \\
\hline 1935 & 49 & 185 & 3.087 & 2.863 & 2.649 & 1.352 & 370 \\
\hline 1936 & 52 & 188 & 3.236 & 3.031 & 2.692 & 1.244 & 521 \\
\hline 1937 & 51 & 172 & 3.440 & 3.223 & 2.916 & 1.415 & 413 \\
\hline 1938 & 51 & 201 & 3.418 & 2.851 & 2.641 & 1.257 & \\
\hline
\end{tabular}

Fonte: IBGE (1941), adaptado pelas autoras.

\section{A educação no sistema regular e seus impeditivos para a pessoa com deficiência}

O Decreto $n^{\circ}$ 19.890/31 (BRASIL, 1931b) dispõe sobre a organização do ensino secundário e, no Capítulo IV, trata do regime escolar e matrícula do aluno dizendo que este deve apresentar atestado de sanidade (Art. 25). A consolidação das disposições do ensino secundário foi feita através do Decreto $n^{\circ} 21.241 / 31$ (BRASIL, 1931c) e pedia, na matrícula 
do aluno, que fosse especificado no atestado de sanidade se este não sofria de doenças contagiosas da vista (item b do Art. 27).

Em 1942, foram promulgados decretos sobre a reforma do ensino secundário, também conhecida como Reforma Capanema (BELLO, 2001). O Decreto-lei $\mathrm{n}^{\circ}$ 4.048/42 (BRASIL, 1942a) criou o Serviço Nacional de Aprendizagem Industrial (SENAI) e, o Decreto-lei $\mathrm{n}^{\circ} 4.073$ (BRASIL, 1942b) regulamentou esse ensino. Neste Decreto-lei, na Seção I do Capítulo VIII, que trata das condições de admissão, diz que

Art. 29. O candidato à matrícula na primeira série de qualquer dos cursos industriais, de mestria, ou técnicos, ou na única série dos cursos pedagógicos, deverá desde logo apresentar prova de não ser portador de doença contagiosa (grifo nosso) e de estar vacinado.

Art. 30. Deverá o candidato satisfazer além das condições gerais referidas no artigo anterior, as seguintes condições especiais de admissão:

I - para os cursos industriais:

c) possuir capacidade física e aptidão mental (grifo nosso) para os trabalhos escolares que devam ser realizados.

II - para os cursos de mestria:

a) ter concluído curso industrial (grifo nosso) correspondente ao curso de mestria que pretenda fazer;

III - para os cursos técnicos:

a) ter concluído o primeiro ciclo do ensino secundário, ou curso industrial relacionado com o curso técnico que pretenda fazer;

b) possuir capacidade física e aptidão mental (grifo nosso) para os trabalhos escolares que devam ser realizados;

IV - para os cursos pedagógicos:

a) ter concluído qualquer dos cursos de mestria ou qualquer dos cursos técnicos (grifo nosso);

Observa-se que, para matricular-se nos cursos industriais, era preciso possuir capacidade física e aptidão mental, e trazer um documento comprobatório de sua condição. Para os cursos de mestria e pedagógicos não era mencionada tal condição, mas a matrícula estava condicionada à conclusão de algum curso industrial (no primeiro caso) e, no segundo caso, de algum curso de mestria ou técnico. Então o "gargalo" continuava sendo: não ser portador de doença contagiosa, possuir capacidade física e aptidão mental.

Através do Decreto-lei no 4.244/42 (BRASIL, 1942c), que regulamentava o ensino secundário e estabelecia a Lei Orgânica, o capítulo que trata da admissão aos cursos diz que se devia apresentar prova de não ser portador de doença contagiosa e ser vacinado (Art. 31). O ensino comercial foi regulamentado pelo Decreto-lei $n^{\circ}$ 6.141/43 (BRASIL, 1943), no qual, na Seção I, inserida no Capítulo IV, que trata da vida escolar, diz que

Art. 20. O candidato a matricula inicial em qualquer dos cursos de formação deverá apresentar prova de não ser portador de doença contagiosa e de estar vacinado (grifo nosso).

Art. 21. Além das condições referidas no artigo anterior, deverá o candidato satisfazer o seguinte:

b) Ter revelado, em exame de admissão, aptidão intelectual (grifo nosso) para os estudos a serem feitos.

Na década de 1940, foram baixados novos decretos para o ensino primário, normal, comercial e agrícola. O Decreto-lei $\mathrm{n}^{\circ}$ 8.529/46 (BRASIL, 1946b) regulamentou o ensino primário pela Lei Orgânica do Ensino Primário. É muito interessante observar, nesse 
decreto, a ausência dos impeditivos à matrícula mencionada nos decretos anteriores. Porém, ao mencionar no Art. 16 a necessária maturidade para os estudos, fica a dúvida se a criança com algum tipo de deficiência podia ser aceita na escola, considerando a visão de deficiência que se tinha na época.

O Decreto-lei $\mathrm{n}^{\circ}$ 8.530/46 (BRASIL, 1946c) regulamenta o ensino normal, com as seguintes finalidades (Art. $1^{\circ}$ )

1. Prover à formação do pessoal docente necessário às escolas primárias.

2. Habilitar administradores escolares destinados às mesmas escolas.

3. Desenvolver e propagar os conhecimentos e técnicas relativas à educação da infância.

De acordo com esse decreto-lei, para admissão, administrativa ou docente, ao curso de qualquer dos ciclos de ensino normal, serão exigidas do candidato algumas condições (Art. 20); dentre essas,
b) sanidade física e mental;
c) ausência de defeito físico ou distúrbio funcional que contra-indique o exercício da função docente;
d) bom comportamento social;

Então, para uma pessoa adulta com deficiência também havia impeditivos para lecionar. Mas o mais provável é que a pessoa com algum tipo de deficiência, considerandose as condições da época, não chegaria a este nível de ensino. Há exceções, conforme mostra o quadro a seguir (Quadro 2), principalmente para a pessoa com deficiência visual.

QUADRO 2 - A inserção da pessoa com deficiência ao sistema educacional

\begin{tabular}{|c|c|}
\hline LEGISLAÇÃO & O QUE TRATA \\
\hline $\begin{array}{l}\text { Parecer } n^{0} .291 / 33 \text { da Comissão do Ensino } \\
\text { Secundário do Conselho Nacional da Educação }\end{array}$ & $\begin{array}{l}\text { Permite o ingresso de aluno cego em escola do sistema regular de } \\
\text { ensino na cidade de Curitiba. }\end{array}$ \\
\hline Decreto-Lei no ${ }^{\circ} .770$ de 28 de outubro de 1941 & $\begin{array}{l}\text { Dá o direito dos cegos ingressarem no serviço público para o } \\
\text { exercício compatível com a sua deficiência. }\end{array}$ \\
\hline Decreto-lei ${ }^{0} 5.895$, de 20 de outubro de 1943 & $\begin{array}{l}\text { Dispõe sobre o aproveitamento de indivíduos com capacidade } \\
\text { reduzida no mercado de trabalho }\end{array}$ \\
\hline Decreto $n^{\circ} .14 .165 / 43$ & $\begin{array}{l}\text { Dá ao Instituto Benjamin Constant competência para ministrar o } \\
\text { ensino primário e secundário. }\end{array}$ \\
\hline $\begin{array}{l}\text { Parecer no. 144/43 da Comissão de Legislação } \\
\text { do Conselho Nacional de Educacão. }\end{array}$ & $\begin{array}{l}\text { Autoriza a inscrição de aluno cego na Faculdade de filosofia, } \\
\text { Ciências e Letras. }\end{array}$ \\
\hline $\begin{array}{l}\text { Portaria Ministerial } n^{\circ} .385 \text { de } 8 \text { de junho de } \\
1946\end{array}$ & $\begin{array}{l}\text { Equipara o curso ginasial mantido pelo IBC ao ginásio de ensino } \\
\text { comum. }\end{array}$ \\
\hline Portaria Ministerial n'. 12 de 10 de janeiro 1953 & $\begin{array}{l}\text { Autoriza a matrícula de alunos cegos nos estabelecimentos de } \\
\text { ensino secundário, reconhecidos ou equiparados pelo Governo } \\
\text { Federal. Autoriza também a interpretação da legislação de ensino, } \\
\text { pelo Conselho Nacional de Educação, para facultar o acesso de } \\
\text { cegos nos cursos universitários. }\end{array}$ \\
\hline
\end{tabular}

Fonte: As autoras, adaptado de Guerreiro e Villela (2011).

O Decreto-lei $\mathrm{n}^{\circ}$ 8.621/46 (BRASIL, 1946d) cria o Serviço Nacional de Aprendizagem Comercial - SENAC e o Decreto-lei nº 8.622/46 (BRASIL, 1946e) dispõe sobre a aprendizagem de seus associados. As condições para a admissão dos candidatos são:

a) ter concluído o curso primário ou possuir os conhecimentos mínimos essenciais à preparação profissional; 
b) ter aptidão física e mental, verificada, por processo de seleção profissional, para a atividade que pretendam exercer (grifo nosso);

c) não sofrer de moléstia contagiosa, e ser vacinado contra a varíola (grifo nosso)

O ensino agrícola, regulamentado pelo Decreto-lei $n^{\circ}$ 9.613/46 (BRASIL, 1946f), também solicita, na matrícula do aluno, prova de ele não ser portador de doença contagiosa e de estar vacinado (Art. 25), além de (Art. 26):

I. Para o Curso de Iniciação Agrícola:

c) possuir capacidade física e aptidão mental para os trabalhos escolares que devam ser realizados (grifo nosso);

II. Para o Curso de Mestria Agrícola:

b) possuir capacidade física para os trabalhos escolares que devam ser realizados (grifo nosso);

III. Para os cursos agrícolas ou o Curso de Magistério de Economia Rural Doméstica:

b) possuir capacidade física para os trabalhos escolares que devam ser realizados (grifo nosso);

IV. Para o Curso de Didática do Ensino Agrícola ou o Curso de Administração do Ensino Agrícola:

a) ter concluído qualquer dos cursos agrícolas técnicos;

Para Jannuzzi (2004), a concepção de deficiência na época estava muito ligada ao coeficiente intelectual (QI), e este ligado ao rendimento escolar. De fato, é o que refletem os decretos anteriormente citados (Quadro 3). Naquele contexto, a proposta pedagógica estava na montagem de classes homogêneas, portanto, a educação das pessoas com deficiências somente poderia se dá em classes especiais ou em instituições especializadas. Essas concepções se refletiram nas leis. Desta feita, a educação que era para todos excluía a pessoa com deficiência.

QUADRO 3 - Critérios para a matrícula na escola

\begin{tabular}{|c|c|}
\hline LEGISLAÇÃO & SOLICITAÇÃO/IMPEDITIVO \\
\hline Decreto $^{0} 19.890 / 31$ & Atestado de sanidade \\
\hline 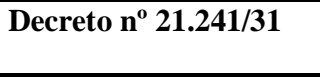 & $\begin{array}{l}\text { Atestado de sanidade, especificando que o candidato não sofre de doenças contagiosas da } \\
\text { vista }\end{array}$ \\
\hline Decreto-lei $n^{\circ}$ 4.048/42 & Não ser portador de doença contagiosa; possuir capacidade física e aptidão mental \\
\hline Decreto-lei $\mathrm{n}^{\circ}$ 4.244/42 & Não ser portador de doença contagiosa \\
\hline Decreto-lei no 6.141/43 & Não ser portador de doença contagiosa; aptidão intelectual \\
\hline Decreto-lei $\mathrm{n}^{\circ} 8.529 / 46$ & Necessária maturidade para os estudos \\
\hline Decreto-lei $\mathrm{n}^{\circ} \mathrm{8.530/46}$ & Sanidade física e mental; ausência de defeito físico ou distúrbio funcional \\
\hline Decreto-lei no 8.622/46 & Aptidão física e mental; não sofrer de moléstia contagiosa \\
\hline Decreto-lei no 9.613/46 & Possuir capacidade física e aptidão mental \\
\hline
\end{tabular}

Fonte: As autoras, adaptado de Guerreiro e Villela (2011).

Glat e Fernandes (2005), por sua vez, afirmam que a educação escolar da pessoa com deficiência não era considerada necessária, ou possível, principalmente para quem tinha deficiências cognitivas e/ou sensoriais severas. Segundo Jannuzzi (2004), a educação da pessoa com deficiência não estava atrelada diretamente ao desenvolvimento econômico de nosso país, mas era voltado para o desenvolvimento das habilidades manuais necessárias à sociedade agrária-comercial-dependente.

Miranda (2003) observa que as mudanças na educação nas décadas de 1930 e 1940 não atingiam a educação do deficiente intelectual, pois a preocupação era com a educação 
da pessoa normal. Isto pode explicar, em parte, a ausência da menção da pessoa com deficiência nas legislações educacionais da época. De acordo com essa autora, na década de 1950, aconteceu uma rápida expansão das classes e escolas especiais nas instituições públicas, e escolas especiais comunitárias privadas e sem fins lucrativos.

Conforme Lautert (2010), a década de 50 foi um período histórico decisivo para o desenvolvimento econômico nacional, principalmente a partir de 1953 com a participação do capital estrangeiro.

\section{Panorama atual}

O panorama atual é bem diferente do tratado nos itens anteriores deste estudo. Houve vários avanços em termos de legislação, que tratam tanto dos direitos da pessoa com deficiência de uma forma geral, quanto dos direitos específicos na área educacional, dentro do sistema regular de ensino. Para Sigolo, Guerreiro e Cruz (2010), apesar desse avanço, ainda é grande a insatisfação com o atendimento escolar oferecido a essa população, pois existe uma distância entre o que acontece no interior das escolas e o que as políticas educacionais traçam como metas e prioridades do governo.

Foi possível identificar, tanto por meio da internet, em sites governamentais, periódicos e documentos, quanto em livros e artigos impressos até o ano de 2011, um total de quatro leis, doze decretos, cinco portarias, cinco resoluções que tratam de temas relacionados à questão da deficiência, além da Política de Educação Especial na Perspectiva da Educação Inclusiva (BRASIL, 2008), neste início de século (Gráfico 1 e Quadro 4).

Essa mudança é fruto do Modelo Social ${ }^{6}$, que vê a deficiência e a pessoa com deficiência como resultados do modo pelo qual a sociedade está organizada. Como a sociedade tem problemas de organização, a pessoa com deficiência, em consequência deste quadro, enfrenta discriminação e barreiras para sua participação.

Segundo Diniz (2003), os argumentos que deram origem ao Modelo Social resumiam-se, basicamente, ao fato de que o corpo lesado não determina, tampouco explica, o fenômeno social e político da subalternidade das pessoas com deficiência. Conclui que a explicação para o baixo nível educacional ou para o desemprego de uma pessoa com deficiência não deveria ser buscada nas restrições provocadas pela lesão, mas nas barreiras sociais que limitam a expressão de suas capacidades.

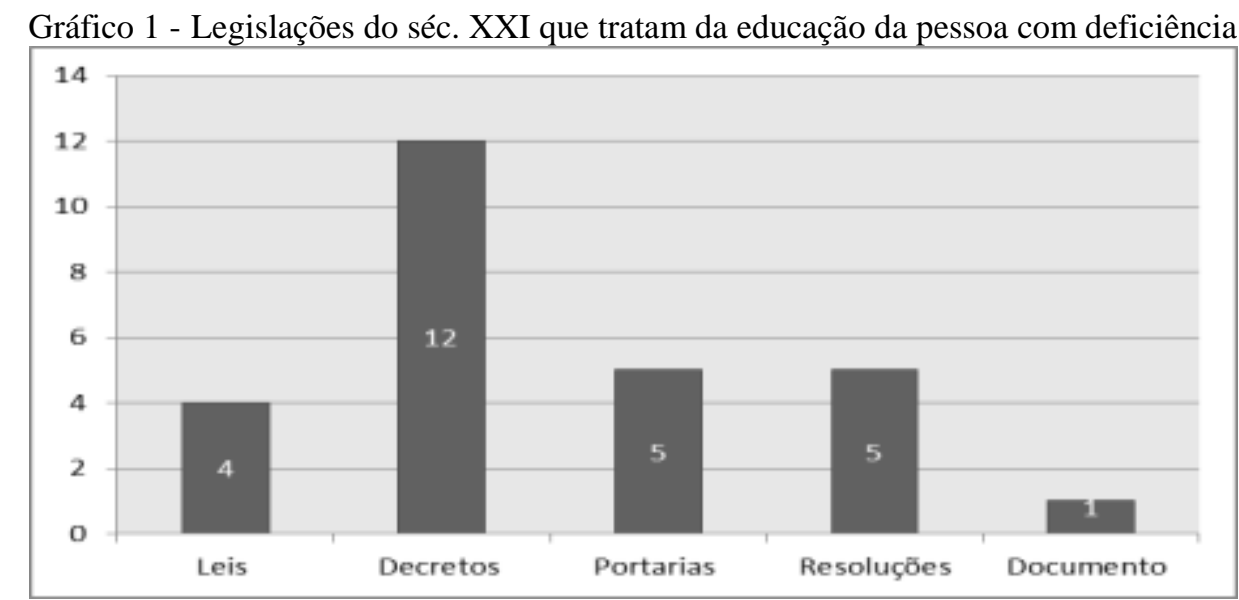

Fonte: As autoras, adaptado de Guerreiro e Villela (2011). 
QUADRO 4 - Legislações do séc. XXI que tratam da educação da pessoa com deficiência

\begin{tabular}{|c|c|}
\hline \multicolumn{2}{|r|}{ LEIS } \\
\hline Lei no. 10.172/01 & Plano Nacional de Educação \\
\hline Lei no. 10.436/02 & Língua Brasileira de Sinais \\
\hline Lei n 10.845/04 & $\begin{array}{l}\text { Programa de Complementação ao Atendimento Educacional Especializado às Pessoas } \\
\text { Portadoras de Deficiência }\end{array}$ \\
\hline Lei n' 11.494/07 & $\begin{array}{l}\text { Fundo de Manutenção e Desenvolvimento da Educação Básica e de Valorização dos } \\
\text { Profissionais da Educação - FUNDEB }\end{array}$ \\
\hline \multicolumn{2}{|r|}{ DECRETOS } \\
\hline Decreto $\mathrm{n}^{\circ} .3 .952 / 01$ & Conselho Nacional de Combate à Discriminação \\
\hline Decreto $\mathrm{n}^{\circ} . \mathbf{3 . 9 5 6 / 0 1}$ & $\begin{array}{l}\text { Convenção Interamericana para a Eliminação de Todas as Formas de Discriminação contra } \\
\text { as Pessoas Portadoras de Deficiência }\end{array}$ \\
\hline Decreto $n^{0} .5 .296 / 04$ & Regulamenta as Leis 10.048 e 10.098 com ênfase na promoção de acessibilidade \\
\hline Decreto $\mathrm{n}^{\circ} .5 .626 / 05$ & Regulamenta a Lei 10.436 que dispõe sobre a língua Brasileira de Sinais - Libras \\
\hline Decreto $n^{0} .6 .215 / 07$ & Comitê Gestor de Políticas de Inclusão das Pessoas com Deficiência \\
\hline Decreto $\mathrm{n}^{0} .6 .214 / 07$ & Benefício de prestação continuada da assistência social devida à pessoa com deficiência \\
\hline Decreto $^{0}$ 6.253/07 & $\begin{array}{l}\text { Fundo de Manutenção e Desenvolvimento da Educação Básica e de valorização dos } \\
\text { Profissionais da Educação - FUNDEB, regulamenta a Lei no }{ }^{\circ} 11.494 / 07\end{array}$ \\
\hline Decreto $n^{\circ} .186 / 08$ & $\begin{array}{l}\text { Convenção sobre Direitos Humanos das Pessoas com Deficiência e de seu Protocolo } \\
\text { Facultativo assinado }\end{array}$ \\
\hline Decreto $\mathrm{n}^{\circ} .6 .571 / 08$ & Atendimento educacional especializado \\
\hline Decreto $n^{\circ} .6 .949 / 09$ & Convenção Internacional sobre os direitos das pessoas com deficiência \\
\hline Decreto $\mathrm{n}^{\circ} .7 .611 / 11$ & Educação Especial e Atendimento educacional especializado \\
\hline Decreto $\mathrm{n}^{\circ} .7 .612 / 11$ & Plano Nacional dos Direitos da Pessoa com Deficiência - Plano Viver sem Limite \\
\hline \multicolumn{2}{|r|}{$\begin{array}{l}\text { PORTARIAS } \\
\end{array}$} \\
\hline Portaria $\mathrm{n}^{0} .657 / 02$ & Comissão Brasileira de Estudos e Pesquisa do Soroban \\
\hline Portaria $\mathrm{n}^{0} .3 .284 / 03$ & $\begin{array}{l}\text { Acessibilidade de pessoas portadoras de deficiências, para instruir os processos de } \\
\text { autorização e de reconhecimento de cursos, e de credenciamento de instituições de nível } \\
\text { superior }\end{array}$ \\
\hline Portaria $\mathrm{n}^{0} .976 / 06$ & Dispõe sobre os critérios de acessibilidade aos eventos do Ministério da Educação \\
\hline Portaria $n^{0} .6$ de 5/08 & $\begin{array}{l}\text { Grupo de Trabalho para realizar estudos e definir diretrizes voltadas para a escolarização } \\
\text { de alunos com transtornos funcionais específicos }\end{array}$ \\
\hline Portaria n $^{0} 2.344 / 10$ & $\begin{array}{l}\text { Atualiza a nomenclatura do Regimento Interno do CONADE, aprovado pela Resolução }{ }^{\circ} \\
35 \text {, de } 06 \text { de julho de 2005, para Pessoas com Deficiência }\end{array}$ \\
\hline \multicolumn{2}{|r|}{ RESOLUÇÕES } \\
\hline $\begin{array}{l}\text { Resolução CNE/CEB } \\
\text { no }^{0} .02 / 01\end{array}$ & Diretrizes Nacionais para a Educação Especial na Educação Básica \\
\hline $\begin{array}{l}\text { Resolução CNE/CP n } \\
\text { 01/02 }\end{array}$ & Diretrizes Curriculares Nacionais para a Formação de Professores da Educação Básica. \\
\hline $\begin{array}{l}\text { Resolução CNE/CEB, } \\
\text { n }^{0} \text { 1/04 }\end{array}$ & $\begin{array}{l}\text { Diretrizes Nacionais para a organização e a relação de Estágios dos alunos da Educação } \\
\text { Profissional e do Ensino Médio, inclusive nas modalidades de Educação Especial e de } \\
\text { Educação de Jovens e Adultos }\end{array}$ \\
\hline Resolução n' 2/08 & $\begin{array}{l}\text { Diretrizes complementares, normas e princípios para o desenvolvimento de políticas } \\
\text { públicas de atendimento da Educação Básica do Campo }\end{array}$ \\
\hline $\begin{array}{l}\text { Resolução CNE/CEB } \\
\text { n }^{\circ} .04 / 09\end{array}$ & $\begin{array}{l}\text { Institui as Diretrizes Operacionais para o Atendimento Educacional Especializado na } \\
\text { Educação Básica, modalidade Educação Especial }\end{array}$ \\
\hline \multicolumn{2}{|r|}{ DOCUMENTO } \\
\hline $\begin{array}{l}\text { Documento elaborado } \\
\text { pelo GT nomeado } \\
\text { pelas Portarias } n^{\circ} \text {. } \\
555 / 07 \text { e } 948 / 07\end{array}$ & Política Nacional de Educação Especial na perspectiva da Educação Inclusiva (2008) \\
\hline
\end{tabular}

Fonte: As autoras, adaptado de Guerreiro e Villela (2011).

A forma de identificação da pessoa com deficiência, também, passou por modificações, à medida que a temática foi sendo posta em debates e questionamentos. De acordo com Lanna Júnior (2010), as palavras usadas para nomear as pessoas com deficiência partem de uma visão valorativa que traduz as percepções da época em que foram estabelecidas (Quadro 5). Esse novo panorama atinge todos os setores ou ambientes de uma 
sociedade, tanto na área educacional quanto na área do direito, médica, esportiva, trabalhista, construção civil, arquitetura, entre outras.

Quadro 5 - Formas de identificação da pessoa com deficiência ao longo do tempo

\begin{tabular}{|c|c|c|}
\hline DENOMINAÇÃO & ÉPOCA & VISÃO \\
\hline $\begin{array}{l}\text { "Inválidos", "Incapazes", } \\
\text { "Aleijados", "Defeituosos" }\end{array}$ & $\begin{array}{l}\text { Foram amplamente utilizados } \\
\text { difundidos até meados do século XX }\end{array}$ & Fardo social, inútil e sem valor \\
\hline "Pessoas deficientes" & $\begin{array}{l}\text { Final da década de } 1970 \text { e início da } \\
\text { década de 1980, por influência do Ano } \\
\text { Internacional das Pessoas Deficientes } \\
\text { (AIPD) }\end{array}$ & $\begin{array}{l}\text { A inclusão do substantivo "pessoa" para } \\
\text { evitar a coisificação, contrapondo à } \\
\text { inferiorização e desvalorização associada } \\
\text { aos termos pejorativos usados }\end{array}$ \\
\hline $\begin{array}{l}\text { "Pessoas portadoras de } \\
\text { deficiência" }\end{array}$ & $\begin{array}{l}\text { A expressão foi adotada na Constituição } \\
\text { Federal de } 1988 \text { e nas estaduais, bem } \\
\text { como em todas as leis e políticas } \\
\text { pertinentes ao campo das deficiências. }\end{array}$ & $\begin{array}{l}\text { A inclusão do adjetivo "portadora" com o } \\
\text { objetivo de identificar a deficiência como } \\
\text { um detalhe da pessoa }\end{array}$ \\
\hline $\begin{array}{l}\text { "Pessoas com necessidades } \\
\text { especiais" e "Portadores de } \\
\text { necessidades especiais" }\end{array}$ & $\begin{array}{l}\text { Eufemismos foram adotados na década de } \\
1990\end{array}$ & $\begin{array}{l}\text { A condição de "portador" passou a ser } \\
\text { questionada pelo movimento por } \\
\text { transmitir a ideia de a deficiência ser algo } \\
\text { que se porta e, portanto, não faz parte da } \\
\text { pessoa }\end{array}$ \\
\hline "Pessoa com deficiência" & $\begin{array}{l}\text { A expressão foi consagrada pela } \\
\text { Convenção sobre os Direitos das Pessoas } \\
\text { com Deficiência, da Organização das } \\
\text { Nações Unidas (ONU), em } 2006\end{array}$ & $\begin{array}{l}\text { Pessoa com deficiência passou a ser a } \\
\text { expressão adotada para designar esse } \\
\text { grupo social }\end{array}$ \\
\hline
\end{tabular}

Fonte: Lanna Júnior (2010), sistematizado pelas autoras.

A questão do direito da pessoa com deficiência é discutida na mídia; junto com as Olimpíadas são realizadas as Paraolimpíadas; existem as reservas de vagas para emprego, na indústria, especificamente para pessoas com deficiências; o desenho universal vem discutir a questão do espaço para todos, inclusive para as pessoas com deficiência; em 2009, foi nomeado o primeiro juiz cego na história do Brasil. Estes são marcos importantes conquistados pela luta e perseverança de vários atores com e sem deficiência. Mas existem muitas questões a serem discutidas e ampliadas, principalmente na educação.

Ainda perduram dúvidas sobre o entendimento da área da Educação Especial e seu alunado, sobre a função do Atendimento Educacional Especializado - AEE, critérios de financiamento e lócus de ensino. A localização atual no organograma do Ministério da Educação, antes na Secretaria de Educação Especial - SEESP e agora em uma Diretoria de Políticas de Educação Especial, dentro da Secretaria de Educação Continuada, Alfabetização, Diversidade e Inclusão - SECADI, pode colocar fora de foco as necessidades e especificidades da área da Educação Especial.

De acordo com Guerreiro (2011), a Educação Especial é uma área multiprofissional e multidisciplinar, e abarcá-la é uma tarefa complexa e inacabada, já que está sempre caminhando, construindo, desconstruindo, e aprendendo. Ora ela precisa de uma visibilidade específica, ora precisa estar implícita no sistema educacional de forma não diferenciada. As questões estão em discussão, mas fica uma certeza de que, embora o direito à educação da pessoa com deficiência esteja consolidado, ainda há muito terreno a ser avançado e espaço a ser construído para se fazer história.

\section{Referências}

ANDREOTTI, A. L. O projeto de ascensão social através da educação escolarizada na década de 1930. 2004. Disponível em: <http://www. histedbr.fae.unicamp.br/navegando/ 
artigos_frames/artigo_023.html>. Acesso em: 16 nov. 2011.

BAZÍLIO, L. C.; MÜLLER, T. M. P. Justiça versus educação: a criança no governo Vargas. Anais... VI Congresso Luso-Brasileiro de História da Educação, 2006, Uberlândia, Minas Gerais. Disponível em: < http://www.faced.ufu.br/colubhe06/anais

</arquivos/eixo7.htm>. Acesso em: 15 nov. 2011.

BELLO, J. L. P. Educação no Brasil: a História das rupturas. Pedagogia em Foco, Rio de Janeiro, 2001. Disponível em: < http://www.pedagogiaemfoco.pro.br/heb14.htm>. Acesso em: 5 set. 2011.

BRASIL. Constituição da República dos Estados Unidos do Brasil, de 24 de fevereiro de 1891. Disponível em: <http://www.planalto.gov.br/ccivil_03/constituicao/

Constituicao91.htm> Acesso em: 5 set. 2011.

BRASIL. Decreto $n^{\circ} 19.402$, de 14 de novembro de 1930b. Disponível em: $<$ http://portal.mec.gov.br/index.php?option=com_content $\&$ view=article \&id=2\&Itemid=171 >. Acesso em: 5 set. 2011.

BRASIL. Decreto $n^{o} 19.850$, de 11 de abril de 1931a. Disponível em: <http://www6.senado.gov.br/legislacao/ListaPublicacoes.action?id=4024>. Acesso em: 5 set. 2011.

BRASIL. Decreto $n^{\circ} 19.890$, de 18 de abril de 1931b. Disponível em:

<http://www.histedbr.fae.unicamp.br/navegando/fontes_escritas/5_Gov_Vargas/decreto $\% 20$ 19.890-\%201931\%20reforma\%20francisco\%20campos.htm>. Acesso em: 5 set. 2011.

BRASIL. Decreto $n^{\circ} 21.241$, de 14 de abril de 1931c. Disponível em: <http://www.histedbr.fae.unicamp.br/navegando/fontes_escritas/5_Gov_Vargas/decreto\%20 21.241-1932\%20reforma\%20francisco\%20campos.htm>. Acesso em: 5 set. 2011.

BRASIL. Constituição da República dos Estados Unidos do Brasil, de 16 de julho de 1934a. Disponível em: <http://www.planalto.gov.br/ccivil_03/constituicao/constitui\%C3 \%A7ao34.htm>. Acesso em: 5 set. 2011.

BRASIL. Decreto $n^{\circ}$ 24.794, de 14 de julho de 1934b. Cria, no Ministério da Educação e Saúde Pública, sem aumento de despesa, a Inspetoria Geral do Ensino Emendativo, dispõe sobre o Ensino do Canto Orfeônico, e dá outras providências. Disponível em: <http://www. esporte.gov.br/cedime/legislacao/leisEdFisica.jsp\#1934>. Acesso em: 15 nov. 2011.

BRASIL. Constituição dos Estados Unidos do Brasil, de 10 de novembro de 1937. Disponível em: <http://www. planalto.gov.br/ccivil_03/constituicao/constitui\%C3\%A7 ao37.htm>. Acesso em: 5 set. 2011.

BRASIL. Decreto-lei $n^{\circ} 4.048$, de 22 de janeiro de 1942a. Disponível em: <http://www 010.dataprev.gov.br/sislex/paginas/24/1942/4048.htm>. Acesso em: 5 set. 2011.

BRASIL. Decreto-lei $n^{\circ} 4.073$, de 30 de janeiro de 1942b. Lei Orgânica do ensino Industrial. Disponível em: <http://www010.dataprev.gov.br/sislex/paginas/24/1942/4073. htm>. Acesso em: 5 set. 2011.

BRASIL. Decreto-lei $n^{\circ}$ 4.244, de 9 de abril de 1942c. Disponível em: <http://www.soleis.adv.br/leiorganicaensinosecundario.htm>. Acesso em: 5 set. 2011. 
BRASIL. Decreto-lei $n^{\circ}$ 6.141, de 28 de dezembro de 1943. Disponível em: <http://www. cosif.com.br/mostra.asp?arquivo=dec-lei6141-1943>. Acesso em: 5 set. 2011.

BRASIL. Constituição dos Estados Unidos do Brasil, de 18 de setembro de $1946 a$. Disponível em: <http://www.planalto.gov.br/ccivil_03/constituicao/constituicao46.htm>. Acesso em: 5 set. 2011.

BRASIL. Decreto-lei $n^{\circ} 8.529$, de 2 de janeiro de 1946b. Disponível em: <http://www.soleis.adv.br/leiorganicaensinoprimario.htm>. Acesso em: 5 set. 2011.

BRASIL. Decreto-lei $n^{o} 8.530$, de 2 de janeiro de 1946c. Disponível em: <http://www.soleis.adv.br/leiorganicaensinonormal.htm>. Acesso em: 5 set. 2011.

BRASIL. Decreto-lei $n^{\circ}$ 8.621, de 10 de janeiro de 1946d. Disponível em: <http://www1. sp.senac.br/hotsites/arquivos_materias/decreto-lei_8621de10-01-1946.pdf>. Acesso em: 5 set. 2011.

BRASIL. Decreto-lei $n^{\circ}$ 8.622, de 10 de janeiro de 1946e. Disponível em: <http://www1.sp.senac.br/hotsites/arquivos_materias/DEL_008622_46.pdf>. Acesso em: 5 set. 2011.

BRASIL. Decreto-lei $n^{o}$ 9.613, de 20 de agosto de 1946f. Disponível em: <http://www.soleis.adv.br/leiorganicaensinoagricola.htm>. Acesso em: 5 set. 2011.

BRASIL. Lei $n^{\circ} 1.920$, de 25 de julho de 1953. Disponível em: <http://www6.senado.gov.br/legislacao/ListaPublicacoes.action?id=109070>. Acesso em: 5 set. 2011.

BRASIL. Lei $n^{\circ}$ 4.024, de 20 de dezembro de 1961. Disponível em: <http://wwwp.fc.unesp.br/ lizanata/LDB\%204024-61.pdf>. Acesso em: 5 set. 2011.

CURY, C. R. J. A educação escolar, a exclusão e seus destinatários. Educação em Revista, Belo Horizonte, n. 48, p. 205-222, dez, 2008.

DAVIES, N. Os conflitos durante a tramitação do projeto que resultou na primeira LDB (a lei 4024): conflitos apenas educacionais ou de projeto de sociedade? Disponível em: <http://www.uff.br/feuff/departamentos/politica_mural.htm>. Acesso em: 5 set. 2011.

DINIZ, D. Modelo social da deficiência: a crítica feminista. In: Série Anis 28, Brasília, DF: LetrasLives, julho, 2003, p. 1-8. Disponível em:

<http://www.anis.org.br/serie/artigos/sa28(diniz)deficienciafeminismo.pdf >. Acesso em: 25 mai. 2013.

FARIA, E. V. de; FARIA, S. M. V. Educação de jovens e adultos no Brasil: dos discursos às práticas. Rev. Teoria e Prática da Educação, v.8, n.2, p.243-252, mai./ago. 2005.

Disponível em: <http://www.dtp.uem.br/rtpe/volumes/v8n2/art11.pdf >. Acesso em: 5 set. 2011.

FERREIRA, J. R. A exclusão da diferença: a educação do portador de deficiência. 2 ed. Piracicaba: UNIMEP, 1994.

GLAT, R.; FERNANDES, E. M. Da educação segregada à educação inclusiva: uma breve reflexão sobre os paradigmas educacionais no contexto da educação especial brasileira. Revista Inclusão n. 1, 2005, MEC/SEESP.

GUERREIRO, E. M. B. R. Avaliação da satisfação do aluno com deficiência no ensino superior: estudo de caso da UFSCar. 2011. 229f. Tese (Doutorado em Educação Especial) Revista HISTEDBR On-line, Campinas, $n^{\circ}$ 52, p. 183-197, set2013 - ISSN: 1676-2584 
Centro de Educação e Ciências Humanas, Programa de Pós-Graduação em Educação Especial / Universidade Federal de São Carlos - PPGEEs/UFSCar, São Carlos-SP, 2011.

GUERREIRO, E. M. B. R.; VILLELA, T. C. R. A invisibilidade da pessoa com deficiência na legislação educacional brasileira de 1930 a 1961: o que mudou no século XXI? In: DENARI, F. E. Educação e Educação Especial: textos e con(textos). São Carlos-SP: Pedro \& João Editores, 2011.

INSTITUTO BRASILEIRO DE GEOGRAFIA E ESTATÍSTICA - IBGE. Repertório Estatístico do Brasil: quadros retrospectivos. ${ }^{\circ}$ 1, Ano V. 1941. Disponível em: <http: //biblioteca.ibge.gov.br/visualizacao/monografias/GEBIS\%20$\% 20 \mathrm{RJ} /$ seriesestatisticasrestrospectivas/Volume\%201_Repertorio\%20estatistico\%20do\%20 Brasil_Quadros\%20retrospectivos\%20n\%201.pdf>.Acesso em: 16 nov. 2011.

INSTITUTO NACIONAL DE ESTUDOS E PESQUISAS EDUCACIONAIS ANÍSIO TEIXEIRA - INEP. A educação nas mensagens presidenciais. V. 1. Brasília: MEC/INEP 1987a. Disponível em: <http://www. dominiopublico.gov.br/download/texto/ me001516.pdf >. Acesso em: 5 set. 2011.

INSTITUTO NACIONAL DE ESTUDOS E PESQUISAS EDUCACIONAIS ANÍSIO TEIXEIRA. A educação nas mensagens presidenciais. V. 2. Brasília: MEC/INEP, 1987b. Disponível em: <http://www. dominiopublico.gov.br/download/texto/me001499. pdf>. Acesso em: 5 set. 2011.

JANNUZZI, G. M. Algumas concepções de educação do deficiente. Rev. Bras. Cienc. Esporte, Campinas, v.25, n.3, p. 9-25, maio 2004. Disponível em: <http://www. rbceonline. org.br/revista/index.php/RBCE/article/view/235>. Acesso em: 5 set. 2011.

JANNUZZI, G. M. A educação do deficiente no Brasil: dos primórdios ao início do século XX1. 2. ed. Campinas/SP: Autores Associados, 2006.

LANNA JÚNIOR, M. C. M. História do movimento político das pessoas com deficiência no Brasil. Brasília: Secretaria de Direitos Humanos/Secretaria Nacional de Promoção dos Direitos da Pessoa com deficiência, 2010.

LAUTERT, V. A internacionalização da economia brasileira nos anos de 1950: os atores e suas aspirações. In: ENCONTRO REGIONAL DE ECONOMIA, XIII. 2010, Porto Alegre. Anais...Porto Alegre: UFRGS, 2010. Disponível em:

<http://www.ppge.ufrgs.br//anpecsul2010/artigos/16.pdf>. Acesso em: 5 set. 2011.

MIRANDA, A. A. B. História, deficiência e educação especial. Disponível em: <http://www.histedbr.fae.unicamp.br/revista/revis/revis15/art1_15.pdf >. Acesso em: 5 set. 2011.

SANTOS, Í. F. CAp-UERJ: como e para quem a escola conta sua história? Morpheus Rev. Eletrônica em Ciências Humanas, Ano 4, n. 8, 2006. Disponível em: <http://www. unirio.br/morpheusonline/numero08-2006/isisflora.htm>. Acesso em: 5 set. 2011.

SANTOS, J. Os caminhos e os descaminhos da política educacional brasileira. 2007b. Disponível em: <http://www.gestaouniversitaria.com.br/index.php?option=com content $\&$ view $=$ article $\&$ id=442:os-caminhos-e-os-descaminhos-da-politica-educacional brasileira\&catid=92:130\&Itemid=21>. Acesso em: 5 set. 2011 .

SHIROMA, E. O.; MORAES, M. C. M.; EVANGELISTA, O. Politica Educacional. 4ª ed. Rio de Janeiro: Lamparina, 2007. 
SIGOLO, A. R. L.; GUERREIRO, E. M. B. R.; CRUZ, R. A. S. Políticas educacionais para a Educação Especial no Brasil: uma breve contextualização histórica. In: Práxis Educativa, v.5, n.2, jul./dez., 2010, p. 173-194. Disponível em:

<http://www.periodicos.uepg.br>. Acesso em: 24 mai. 2013.

Notas

\footnotetext{
${ }^{1}$ Instituto Federal de Educação, Ciência e Tecnologia do Amazonas - IFAM. Email: emguerreiro@uol.com.br

${ }^{2}$ Universidade Federal de São Carlos - UFSCar. Email: terezacvillela@ gmail.com

${ }^{3}$ Antigo Imperial Instituto dos Meninos Cegos, criado pelo Imperador D. Pedro II através do Decreto Imperial n. ${ }^{\circ} 1.428$, de 12 de setembro de 1854 .

${ }^{4}$ Atual Instituto Nacional de Educação de Surdos - INES (antigo Imperial Instituto dos Surdos-Mudos), criado pelo Imperador D. Pedro II através da Lei nº. 839, de 26 de setembro de 1857.

${ }^{5}$ Centro Nacional de Educação Especial/MEC.

${ }^{6}$ Disponível em http://www.marking-prsp-inclusive.org/pt6-deficiencia.html.
}

Recebido em setembro-2012

Aprovado em agosto-2013 